https://doi.org/10.18485/iipe_60nam.2021.ch24

\title{
ADJUSTING THE NAM TO NEW GLOBAL REALITIES: EMPLOYING INSTITUTIONAL MEMORY AND EXPLORING BEST PRACTICES
}

\begin{abstract}
Amr ALJOWAILY1,2
Abstract: There can be no better reason to write than to mark the sixtieth anniversary of the Non-Aligned Movement (NAM). Therefore, this celebration prompted the author to prepare a paper that presents his personal experience and impressions stemming from almost 30 years of professional diplomatic career and academic practice. The views expressed in this paper on the NAM and multilateralism do not reflect the author's current professional position, but stem from his previous work experience as a consul and plenipotentiary minister in the Egyptian Mission in New York. The paper presents the author's personal observations on the historical development of the NAM and the perspectives for its transformation. The author goes back with nostalgia to the time when he had the opportunity to personally participate in the activities of non-aligned countries in the United Nations, and passes on
\end{abstract}

\footnotetext{
${ }^{1}$ Ambassador of the Arab Republic of Egypt to the Republic of Serbia. E-mail: Amr.Aljowaily@gmail.com

An earlier version of this article appeared under the title "The Working 'NonAligned Movement" in a book published in 2019: Non-Aligned Movement from Belgrade 1989 to Baku 2019: 30 Years of Transformation in Uncertain Times, Belgrade, PLUS Klub.

${ }^{2}$ I would like to thank Professor Branislav Đorđević, the Director of IIPE in Belgrade, and Duško Dimitrijević, Professorial Fellow and Editor-in-Chief of this precious collection dedicated to the jubilee of the Non-Aligned Movement (NAM). I would also like to extend my warmest congratulations to the Republic of Serbia for the initiative to celebrate the 60th anniversary of the Movement's first summit in Belgrade in 1961.
} 
his rich experience to readers through the prediction of possible directions of development and adaptation of the NAM in global international relations.

Key words: of the Non-Aligned Movement, multilateralism, working groups, international relations.

\section{Between Belgrade and Cairo: The NAM's Leadership Visibility}

The image of the NAM that resonates in our minds is a picture of world leaders from the 1960s who work closely together to achieve a fairer world order. Ever since I landed in Cairo for Belgrade, arriving in Serbia as Egypt's ambassador, Nasser's and Tito's photographs in government buildings and museums have constantly reminded me of the leading role both countries played in establishing and nurturing that diplomatic fervour that forever influenced international affairs. There is hardly a diplomatic function in which I did not represent my country with full honours. Hence, I am very careful when the interlocutors would tell their personal participation or childhood memories of the leaders of both countries in their meetings through the NAM. A visit to the Serbian mission to the United Nations, which is almost halfway between the East and the Hudson River on Manhattan Island, or the Serbian Embassy in Cairo, almost on the banks of the Nile River on Zamalek Island, testifies to the place where the two great leaders met, sat, chatted and together imagined a world order that was fairer and more participatory; whose initial fruits we enjoy today and for which we are always ready to nurture further by adapting the Non-Aligned Movement to the vision of today's geopolitical reality.

\section{New York: The NAM is working}

While I have always been fascinated with this image of world leaders being as close together as possible, assuming by their own hands the highest level of diplomatic engagement of the Non-Aligned Movement, I have never witnessed it myself, nor have I had the opportunity to participate in it first-hand. I have had, however, the chance to discover another dimension of the NAM in a much different context, more of the working level, and by consequence much less known. Global norms, standards, rules and even laws are negotiated and agreed in multilateral frameworks, namely the United Nations. While developing countries 
share generically many concerns and interests, they may lack the capacity to best defend their interest and promote their views individually, especially with the growing complexity of international relations and the increasing intensity of multilateral meetings. Groupings such as the NonAligned Movement and the G77 appear as a viable platform to aggregate interests, divide tasks and multiply impact. They do, hence, remain as relevant players in negotiating multilateral outcomes, thus contributing to the discourse on the issues and themes that are high on the agenda of international relations.

The usual format for such coordination of the NAM in New York is "working groups", whose highlighting feature is that they benefit from the designation of a specific diplomatic mission of a Member of the Movement as Chair of the Group, permanently coordinating its activities and almost solely hosting its meetings, except for those that are held on the UN premises. This endows such NAM coordination with the quality that may be most difficult for any individual mission to enjoy by it alone, which is institutional memory. Many, if not most, diplomatic services, especially those of developing countries, do not dedicate or even promote specialised career paths even for the technical issues that have almost become the defining feature of multilateral relations. Diplomats who arrive in New York are usually overwhelmed with the tasks they are required to perform, and the knowledge they are expected to accumulate. The more their portfolio is technical, the more challenging this initiation phase of their work becomes. Participating in these NAM working groups becomes almost a refuge for these "multilaterally freshmen" diplomats. Reading the background documentation that residue at the archives of the coordinator is surely a rich resource, but not the only one. An equally important avenue of sharing knowledge and transmitting accumulated expertise is through the discussions that are usually interactive given the smaller number of delegates attending and the working level representation compared to the larger NAM plenary meetings that are usually at the ambassadorial level with a wider representation of the NAM's membership. These close discussions immediately reveal the shared views and progressively the fine lines of divergent ones. They usually take place within a collegiate, if not even friendly, atmosphere. A spirit of solidarity emanates therefrom, one that becomes one of the most important tools in defending the "group's" view when negotiating with other parties. Given that many of these meetings take place at the seat of the coordinator's mission rather than at the UN headquarters, the hospitality of the convener adds an important conducive atmosphere for 
developing common positions; which cannot be overestimated for developing a transnational, even transregional, bond among delegates of the NAM. Several of the tasks of these working groups are repetitive, making it more conformable for new delegates to integrate, yet, admittedly, sometimes turning a little monotonous for more experienced representatives. These recurrent drafting tasks also facilitate the elaboration of common documents and positions, as they rely on previously agreed language inherited through generations of representatives, and easily "borrowed" from one forum to the other, particularly from those documents adopted at the Summit, to other more technical and expert level platforms. This is not all without cost, as the price to pay is curtailing, to an extent, the creativity of new "language" and ideas, and adjusting long-standing positions to changing negotiating environments, especially those now emerging within the current challenging phase of multilateralism. The relative ease with which these working groups are able to develop fluid common positions is that each such group is usually dedicated to a technical issue, expectedly less tainted by political divisions. Here, I would recall my personal engagement in New York in both the Working Group on Disarmament coordinated by Indonesia and the Working Group on Peacekeeping coordinated by Morocco. These are technical issues which command much "allegiance" from the concerned diplomats. Even those delegates that are first introduced to the subject when joining their missions to the $\mathrm{UN}$, they quickly develop or even construct a brand of expertise once they become familiar with the seemingly technical terminology, let alone decipher the shared coded language of acronyms and abbreviations.

\section{NAM's New York Spirit and the Visitors}

This is surely a "plus" for the working groups as they gather the experts from the missions, almost leading to an "epistemic" community, accruing knowledge, promoting expertise and consolidating harmony among the participants. Yet it is also one of the shortcomings of such a format as this dimension of commonality may not necessarily extend beyond the frontiers of this closely-knit society. Well, it could, and should, at least extrapolate to the realm of permanent representatives, even if not to the same degree. Even when it does so, and to varying degrees, it still remains within the circle of diplomatic representatives to the NAM. It does not often extend to the other circles of representatives of sectorial or line ministries. After all, there are hardly the NAM forums that gather, 
regularly and institutionally, such "real" technical experts. Most of the efforts that fall in this realm are either one-time events or at best sporadic. They do not elevate to the bond those results from the more institutional working groups, which not only benefit from the intensity and regularity of contact, but thrive on the established professional culture of diplomacy. This shortcoming becomes more acute as the negotiating issues become more technical, necessitating participation from these line ministries, or as initiatives are launched to intentionally bypass this community of technical diplomatic expertise including through involving representatives from other professional cultures. "Specialised diplomats" dedicated to the negotiation of technical issues at the UN headquarters may thus lose part of their influence in the negotiations, or at least may not have the same access to the now more restricted meetings formats, geared mainly for incoming officials who have joined from capital line ministries. The established networks of diplomatic negotiators represented by the working groups thus become less central to the negotiating processes, less able to engage or get the attention of the "new" delegates. There have been a number of initiatives by the NAM to quickly adapt to this. I recall one which I witnessed myself when the Working Group on Peacekeeping devoted one of its meetings to Chiefs of Staff of ministries of defence members of the NAM as they arrived in New York to participate in their first meeting ever on peacekeeping called for by the Secretary-General of the United Nations. An added level of complexity is when the outcomes of such meetings do not follow the standard format of subjecting a draft to intensive negotiations from experts to senior officials. Rather, the outcome may be a document prepared by the convener, and open, almost on a take it or leave basis, to accession for those countries who may want to sign. That leaves little room for amending the draft outcome genuinely if it proves substantially different from the national or group position. The only hope then is that the convener has either undertaken informal consultations to ensure that the draft is shared with main players, or that the convener has kept it at a level sufficiently general for it to be nonobjectionable. In either case, the "traditional" dynamics of the NAM contribution and negotiation of the outcome no longer apply as they would normally in other more structured processes.

\section{The NAM Working Groups from Start to Conclusion of Negotiations}

These NAM working groups are therefore quite instrumental in galvanising the Movement's positions on technical issues that are on the 
agenda of the United Nations, particularly the General Assembly and its subsidiary organs. Their most effective contribution is in formulating initial positions, which are then pronounced as opening discourses or thematic statements. They also usually translate into working papers that are then included as part of the official documentation of the negotiating body or conference. As the negotiations move forward and middle positions are required, the group dynamics change, including the role of the coordinator or Chairman of the Group. That is usual in negotiations, yet more challenging for group positions. That is the reason for which the working groups assign facilitators for sub-themes, who report then to the group for developing the positions further to accommodate for the progress of the negotiations. At some advanced stages though, individual delegations may become more active in defending issues of high priority to their national interest. That does not mean acting in contradiction to the group, as usually such positions would have been included in the first place in the collective papers. It is just that the fervour in defending them, or the degree of flexibility in modifying them, rests, naturally, with those delegations that proposed them in the first place, in coordination with the rest of the group, of course. That is why online coordination and impromptu meetings become more and more important in the advanced phases of negotiations.

\section{The NAM in the Digital Age of Diplomacy}

The NAM working groups have already developed a longstanding tradition of coordination among the group experts by email, which enhances agility that is much needed for ongoing negotiations. Still, there is more room to develop online platforms for such group coordination. An example would be a mobile phone application facilitating access to the NAM's document in general, and that of its working groups focused on specialised multilateral issues. Such an online archive of the Movement's public documents would be a great addition to the ability of the NAM to further develop its common positions and enhance its working methods. This may reflect a specific need of the Movement, given its tradition of having the Presidency undertake the main tasks of the secretariat. In such circumstances and with such variable "nests", it becomes even more important for the NAM to have a single cumulative archive, especially if it is electronic. I recall that a think tank attempted to do so for the NAM documents related to disarmament (NAM Disarmament Database, 2020). One can easily imagine a similar platform 
for all the NAM "literature", in addition to a more interactive platform facilitating "search and rescue" for negotiators who may be badly in need of such assistance in time tight negotiations. By doing so, the rich residual knowledge of diplomats developing the NAM positions over generations would be available not only to the specialised circles, but to the wider public. It would be truly contributing to shaping the global discourse through friendly interactive media. Naturally, it would further anchor a somewhat invisible, and indeed non-invasive, institutionalisation to the NAM that may still conform to its concept of the role of its presidency, members and working methods.

\section{The NAM's Chairs and Coordinators: Continuity and Contiguity}

The NAM's reliance on its presidency without a secretariat provides it with agility and saves it from the administrative costs and functional hurdles of a large bureaucracy. Yet it poses a challenge for its ability to provide ongoing conference services and substantive support to its membership and its leadership alike. It also risks the "evaporation" of knowledge of its principal negotiators with their "repatriation" to their original tasks and diplomatic functions. With a continuing rotation of presidency across constitutive regional groupings and their continents, this test of continuity becomes even more serious. Mechanisms such as troika are an attempt to counterbalance this limitation. However, one cannot avoid asking if there are not even more developed frameworks that can further enhance avenues of cooperation between those countries that undertook the Movement's chairmanship on one hand, and those that assume the coordinator role of its working group on the other hand, with a view to enhancing the Movement's and collective memory, vision, and action without a permanent secretariat nor the traditionally accompanying institutional intergovernmental mechanisms. For this to become an epistemic community among experts in addition to being a forum for official interaction among officials of different levels, an innovative form of gathering former negotiators with current representatives may be needed. One could think of a variable geometry of track I and track II diplomacy not for searching concessions, as is usually the case in negotiation processes, but rather for exploring common positions and sharing expertise as ought to be the case in presumably more harmonious groups such as the NAM. This is not a well-established practice that is easy to emulate. Rather, it is an innovative proposal that merits to be explored further. It will not be without difficulties. In any diplomatic system, this 
model is not without challenges, given that departments may work in silos and the weakness of established channels for transfer of knowledge between generations of negotiators. This may necessitate a multitude of platforms for sharing the experience and passing the expertise. Virtual platforms can prove to be a suitable environment for such interaction. Also, the platforms could become more sustainable with the adaptation of diplomacy to modern conditions after Covid-19. One simple practical idea may even be by inviting the chairs and coordinators to contribute with chapters offering a personal interpretive account of their experience as leading negotiations of the NAM, which would amount from more than simple narration to a more elaborate oral history of the movement and its substantive policy contributions. The example of valedictory dispatches in the British Foreign Ministry may be informative in this respect (Paris, 2015). Thematic volumes may be issued separately, thus readily available for the freshmen negotiators. Such ideas are worth exploring at forums that celebrate the anniversary of the NAM, which may be one rare occasion that will gather by definition all the presidencies and coordinators of the NAM, and by design or coincidence, several generations of negotiators thus helping accumulate expertise within any one delegation and among several of them. An opportunity that should not be missed, and that this book may help create in more than one way to reach for the continuity of the NAM's intellectual contributions and the contiguity of the NAM's negotiators virtually and in presence.

\section{Reaching Out Wider: \\ The NAM's Chairs and Coordinators in the Age of Multistakeholder Diplomacy}

By further anchoring the intellectual contribution to global issues and strengthening the role of its chairs and coordinators, the NAM would be better equipped to reach out to wider circles of actors in international relations. It would also allow for more engagement with the academic, research and civil society. It would reinforce the NAM's multistakeholder diplomacy dimension, a continuously expanding feature of today's multilateral relations. A determining factor of how effective coalitions are in multilateral processes is how good they manage the network of relations with the various actors, governmental and beyond. The NAM has traditionally been focused on intergovernmental processes, focusing on its principal actors through state representatives. That is not to say that there has not been interaction with non-governmental organisations and other 
non-state actors playing a wider role in such multilateral processes. In fact, the working groups may be the most interactive layer of the NAM with such new actors. I was witness to several such encounters at the level of the working group on disarmament where many of the views of the two sides converge. In fact, some would argue that several initiatives that are now attributed to leading NGOs and their coalitions are a continuation of ideas that originated in the NAM, which may have been too slow or too shy to pursue them further in recognition of the obstacles of the negotiating dynamics. The issues of nuclear disarmament are a clear example in this case. The issue of nuclear disarmament represents increasing space available to new actors in multilateralism. It offers new opportunities, but also new challenges. The relationship between developing countries and non-governmental organisations in the multilateral forum is quite complex. Questions regarding representativity, funding and positional orientation often arise, especially when the views are divergent and the seats or staff of some of these NGOs may be more from the Global North than from the South membership composing the NAM. For this reason, it becomes imperative to consolidate a network of "indigenous" think tanks, research centres, non-governmental organisations and other non-state actors relevant to the NAM positions and its membership. The experiment of the South Centre ${ }^{3}$ is instructive in that regard. Could a similar model be developed for the political issues that the NAM deals with within the realm of international peace and security, such as disarmament and peacekeeping? Does it have to be one single permanent institution or could a lighter structure, including through a network of thinkers among its membership, could be developed that would lead by the changing chairmanship? These are legitimate questions to ask and may not be too difficult to answer if there is recognition of this need. It becomes thus imperative to develop a strategy to guide the NAM in promoting its own views and consolidating its negotiating positions making full use of the potential in reaching out and coordinating with the participating non-state actors. Reaching out wider within the changing landscape of multilateral diplomacy is necessary for the NAM to achieve its objectives through a global communications strategy. One cannot exclude social media which

\footnotetext{
${ }^{3}$ On its own website, the South Centre affirms that "within the limits of its capacity and mandate", it "also responds to requests for policy advice and for technical and other support from collective entities of the South such as the Group of 77 (G-77) and China and the Non-Aligned Movement (NAM)."
} 
has become an indispensable platform for actively interacting with other actors and shaping the environment encircling the multilateral negotiations. If the NAM principled positions were better known to the broader public, it would be added value to its negotiating power, especially if it reached them without necessarily going the filtering gatekeepers of institutionalised media. Again, this is a realm where the NAM's Chairs and Coordinators may be best equipped to deal with if they develop the internal working methods of coordination in a way which mandates them to do so in an effective way even with the faster pace of processes and the deeper complications of contemporary global relations.

\section{Adjusting Further on the 'Immediate',} the 'Intermediate' and the 'Ultimate' Levels:

\section{The NAM Adapting to the Changing Global Geoeconomic} and Geopolitical Landscape of Multilateralism

In today's world, the NAM continues to interact at three levels: the immediate one is internal with its own characteristics as a "movement" rather than an "organisation", the intermediate one with the dynamic changes of multilateralism as demonstrated by "multistakeholder diplomacy", and the ultimate one being that of the global geopolitical landscape. The latter was the raison d'être of the NAM born in the age of bipolarity. While the situation has changed with the end of the Cold War, polarity has not disappeared. It may have changed the form and may now be a result of different factors, whether strategic, political, economic or other. Its continuing existence necessitates the NAM. Its changing form necessitates adaptation by the NAM. The growing competition between world powers and blocs in the economic realm, including but not limited to issues of technology and energy may be a form of polarity towards which members of the Movement need to continue to be "non-aligned", focusing instead on the balanced relations and orientation geared for the best service of the needs of their peoples. Developing a vision of non-alignment towards new forms of polarity is not simply a matter of intellectual exercise of reinvigorating the NAM. It also touches on dimensions related to coordination and coalition-building between developing countries. Here comes a call for a deeper analysis of the division of labour and continuing coordination with the "sister" grouping of the G77 (Delcour, 2018, G-77, 2021). With largely overlapping membership, similar overall objectives, and sometimes intersecting agendas, this question becomes more acute in times of transitions and change such as the one we arguably live in. One that 
merits reflection as the NAM membership gathers in Belgrade to celebrate its sixtieth anniversary, almost simultaneously with the yearly more routine high-level convening of the two groupings in New York on the margin of the United Nations General Assembly (UNGA). Any such adjustment in the role of the NAM is also linked to the place of international organisations in general, and the United Nations in particular, within the notion and practise of multilateralism. After all, though born independently, the NAM has become at times synonymous to UN dynamics, as a form or group coalitions within multilateral negotiations and multilateralism. The fate of the latter hence immediately impacts the fate of the former that is the NAM. That is not to say that they cannot live without each other, rather that their lives are impacted by each other. Multilateralism faces multiple challenges, if not crises, all of which reflect on the NAM. The symbiotic relation that has existed between them necessitates mutual recovery from shocks and overcoming obstacles.

\section{After Thoughts: Sixty - No Age for Retirement}

Multilateral forums are often criticised for what they do not, or sometimes one could argue cannot, do. Yet they are little appraised for what they succeed to do, often belittling the functioning mechanisms. This contribution attempts to take as its point of the departure the working level NAM that is undertaking its tasks as best as it could. The aim is not to magnify and say that these are the NAM's most important achievements, nor that they are sufficient for achieving the Movement's objectives and goals. It is simply to recognise the areas where improvements can be made, yet it also identifies those working methods that are producing results. The objective of this brief paper is to highlight lessons learned, promote best practices, and pass takeaways that are useful for other levels of the NAM, or even other forums. The key to effectiveness for group work, including on the multilateral level, remains clear working dynamics, efficient management, and cohesive "professional" culture fortified by intensive interaction geared towards the common goals set through a participatory and intellectually rigorous process of harmonisation divergences and ensuring genuine collective ownership. I would argue that these concepts, which may appear complex in this wording, are in fact simple to apply. They are arguably best demonstrated at the collegiate level of delegates attending as experts on the subject matter. However, they can also be emulated at a higher level if the same approach is followed. In such an instant, the "working level" NAM may make the whole forum "working" 
best to achieve its ideals, which are most needed in today's world and the current state of multilateralism. Additionally, practical proposals offered for the NAM would be further reinforcing its ability to positively impact multilateralism by adapting to its ongoing challenges. These included developing platforms for residual knowledge sharing among generations of chairs and coordinators, widening the network of interaction to impact the world of multistakeholder diplomacy, as well as juxtaposing the notion of non-alignment to the current causes of global polarity while maximising impact through the cooperative relationship with its sister groupings. The resources the NAM could employ are its accumulated negotiating literature and its original guiding principles, which are equally relevant today as they were at the time of its foundations, yet made applicable to today's world through developing its working methods and adjusting the focus of its conceptual lens to today's realities. There could not be a better time to do so than the celebration in Belgrade and no better forum to enlighten the discussion than this pioneering book encompassing a vigorous open exchange between the perspective of academics and the perception of practitioners.

\section{References}

Bryson, Andrew (2010), Parting shots: The perils of ambassadorial predictions, Producer, BBC Radio 4's Parting Shots, 29 September, viewed 15 May 2021, retrieved from https://www.bbc.com/news/uk-politics-11418511

Delcour, Marianne (2018), An Analysis of the Possibility of The NonAligned Movement and the Group of 77 Merging Together, MA International Relations, Leiden University Thesis Global Order in Historical Perspective, viewed 15 May 2021, retrieved from https:// studenttheses.universiteitleiden.nl/access/item\%3A2660026/view

G-77, The Group of 77 at the United Nations, 2021, retrieved from http://www.g77.org

Parris, Matthew (2015), The welcome return of the valedictory dispatch Tom Fletcher's love letter to Lebanon offers hope for the Foreign and Commonwealth Office's lost literary form, 2021, retrieved from https:/ / www.spectator.co.uk/article/ the-welcome-return-of-thevaledictory-dispatch

NAM Disarmament Database, James Martin Center for Nonproliferation Studies (CNS), Middlebury Institute of International Studies at Monterey, 2020, retrieved from http://cns.miis.edu/nam/\#\&panel1-1 